\title{
Sacolas Plásticas: Destinações Sustentáveis e Alternativas de Substituição
}

\author{
Amélia S. F. e Santos, Fernando H. de O. Freire, Brenno L. N. da Costa \\ Departamento de Engenharia de Materiais, UFRN \\ Sati Manrich \\ Departamento de Engenharia de Materiais, UFSCar
}

\begin{abstract}
Resumo: Independentemente do material adotado como melhor estratégia para uso em sacolas, cada um tem um destino final ideal que pode ser: compostagem, reciclagem mecânica, reciclagem energética, aterros sanitários, entre outros. Assim, a infra-estrutura de coleta, identificação e disposição do resíduo pós-consumo desse material deve estar associada à escolha feita para garantir sua sustentabilidade sócio-econômica. Além disso, soluções ainda controversas com relação ao real impacto no meio ambiente, não podem ser condenadas, nem incentivadas, mas devem sim ser avaliadas. Nesse sentido, cabe à comunidade científica fornecer bases sólidas e confiáveis, para que as avaliações sejam baseadas em uma visão global do problema. Foi com esse objetivo que elaboramos o presente trabalho, expondo questões críticas e relatando as diferentes soluções adotadas no mundo, inclusive sobre avaliações de impactos ambientais das diferentes alternativas para minimizar e/ou solucionar os problemas relacionados ao uso de sacolas plásticas.
\end{abstract}

Palavras-chave: Plástico, biopolímero, oxibiodegradável, papel, papel sintético, reciclagem.

\section{Plastic Bags: Sustainable Disposal and Alternative Routes to Their Substitution}

Abstract: Regardless of the material adopted as the best strategy for use in plastic bags, each material has an ideal final disposal, which may be composting, mechanical recycling, energy recycling, sanitary landfills, and others. Therefore, the infrastructure of collection, identification and disposal of post-consumer waste of this material should be tied to the choice made to ensure its socio-economic sustainability. Moreover, solutions that are still controversial in terms of their real environmental impact should be neither condemned nor encouraged - rather, they should be evaluated. In this context, it is up to the scientific community to provide solid and reliable foundations to ensure that such evaluations are based on a global vision of the problem. This was the objective that guided the present work, with an analysis of critical issues and description of the diverse solutions adopted around the world, including environmental impact assessments of the different alternatives to minimize and/or solve the problems pertaining to the use of plastic bags.

Keywords: Plastic, biopolymer, oxibiodegradable, paper, composting, recycling.

\section{Introdução}

O conceito de desenvolvimento sustentável surgiu do questionamento sobre até quando os recursos naturais serão suficientes para sustentar o crescente contingente populacional. A Comissão Mundial do Desenvolvimento e Meio Ambiente, em 1987, após realizar vários estudos, definiu esse conceito como: "atender às necessidades da geração presente sem comprometer a habilidade das gerações futuras de atender as suas próprias necessidades". Assim, o desenvolvimento sustentável se tornou uma prioridade nas políticas mundiais de produção de alimentos, materiais e energia ${ }^{[1]}$.

Historicamente, a inserção e crescimento das sacolas plásticas no mercado, substituindo as tradicionais embalagens de papel, teve início na década de 70. Entre as vantagens do plástico pode-se destacar sua leveza, baixo custo, selabilidade sob calor, transparência, flexibilidade, assepsia e capacidade de suportar peso sem romper-se. Dada essas características, as sacolas descartáveis de plástico convencional, denominadas aqui simplesmente de sacolas plásticas, tem função de facilitar o transporte e proteger os produtos, reduzindo o desperdício que tem um fator de impacto significativo no aquecimento global. De acordo com dados apresentados pelo Instituto Sócio-ambiental dos Plásticos e a Plastivida ${ }^{[2]}$, o impacto decorrente da produção da embalagem plástica é inferior a $20 \mathrm{~g}$ de $\mathrm{CO}_{2}$ emitidos para a atmosfera, enquanto $500 \mathrm{~g}$ de pão fatiado acondicionados nessa embalagem equivale a mais que $200 \mathrm{~g}$ de $\mathrm{CO}_{2}$.
Por outro lado, têm-se os impactos negativos relacionados à vida útil curta e baixa degradabilidade das sacolas plásticas, podendo demorar de 100 a 400 anos para degradar-se no meio ambiente pela ação de raios ultravioletas, umidade e calor; efeito cumulativo; poluição visual devido à disposição nas ruas, parques, praças e ambientes turísticos; entupimentos das vias públicas de drenagem; agravamento dos problemas de chuvas fortes como alagamento, engarrafamentos, etc; interferência negativa na alimentação da vida selvagem; alteração do ecossistema e biodiversidade; foco no crescimento de larvas de mosquitos transmissores de doenças como malária, dengue; etc.

No ambiente marinho, o lixo plástico pode ser carregado por milhares de kilômetros pelas correntes oceânicas, afetando a vida de tartarugas, pássaros, mamíferos marinhos, corais, assim como uma variedade de peixes e crustáceos, sendo um dos importantes problemas ambientais marinhos globais do século $\mathrm{XXI}^{[3-16]}$. Estudos organizados pela Agência de Conservação Oceânica ${ }^{[17]}$ indicam que as sacolas plásticas representam 5,4\% do lixo coletado, são o oitavo item mais comum encontrado e é o primeiro da lista dentre os resíduos perigosos. Dados da ONG Projeto Karumbé, que monitora as tartarugas marinhas da costa Uruguaia, corroboram com esses dados, pois $55 \%$ das causas de animais mortos vivos são provocadas por ingestão de resíduos de origem antropogênica, tais como sacolas plásticas, plásticos rígidos, entre

Autor para correspondência: Amélia S. F. e Santos, Departamento de Engenharia de Materiais, Universidade Federal do Rio Grande do Norte - UFRN Av. Salgado Filho, 3000, Lagoa Nova, CEP 59078-970, Natal, RN, Brasil, e-mail: ameliasfs@ufrnet.br 
outros $^{[18]}$. Esse impacto é ainda maior no caso de tartarugas verdes, representando $2 / 3$ do total de mortes.

Apesar de existirem alternativas às sacolas plásticas, como por exemplo, o uso de sacolas biodegradáveis, sacolas degradáveis, sacolas de papel ou sacolas reutilizáveis, qualquer que seja a alternativa escolhida, há impacto ambiental associado. Desta forma, a decisão de uma comunidade sobre a substituição ou a destinação mais adequada para as sacolas plásticas pós-consumo necessita estar fundamentada no seu contexto socioeconômico e em informações amplas e confiáveis. Este trabalho tem o objetivo apenas de divulgar essas informações e de disponibilizá-las ao público interessado para discussão apropriada do tema em busca de uma maior sustentabilidade para a cadeia das sacolas plásticas.

\section{Destinações das Sacolas Plásticas Pós-Consumo}

Como solução para as sacolas plásticas deve-se incentivar o consumo sustentável das mesmas. Nesse cenário, a redução é o primeiro pilar do consumo responsável, o qual consiste, em primeiro lugar, produzir a menor quantidade de lixo possível e, em segundo lugar, dar ao lixo a melhor destinação, ou seja, aquela que provoca o menor impacto ambiental. Estimativas teóricas calculam que um consumo anual de 520 sacolas é suficiente para uma família de 4 pessoas com compras semanais de 72 itens, embalados em 10 sacolas de supermercado por semana de um total de 52 semanas no ano. Esse número é bem inferior aos praticados pelos consumidores, o qual pode chegar, segundo dados da Nova Zelândia, a um consumo anual de 520 unidades por pessoa ${ }^{[17]}$. Em termos gerais, o número total de sacolas consumidas no Quênia, Austrália, Nova Zelândia e Uruguai são, respectivamente, 0,3, 6, 1,6 e 1,4 bilhões de unidades por ano ${ }^{[17-20]}$, sendo os supermercados o principal distribuidor da cadeia.

O segundo pilar do consumo responsável de sacolas plásticas é a reciclagem mecânica como a melhor destinação do resíduo, porém o índice praticado no mundo todo é muito baixo. A estimativa é que 95\% de todas as sacolas plásticas terminem nos aterros e acabem representando 0,02 a $0,25 \%$ em massa do lixo urbano ${ }^{[17]}$, sendo que $80 \%$ delas já teriam sido reutilizadas. Esse tipo de disposição para os plásticos derivados do petróleo significa desperdício do seu potencial energético. Por isso, as sacolas que não puderem mais ser reutilizadas devem ser limpas e colocadas no lixo reciclável, junto com os demais plásticos. É imprescindível praticar a coleta seletiva do lixo e destinar as sacolas para reciclagem. Atividades de educação ambiental também têm um papel importante na destinação adequada, pois contribui para evitar o descarte incorreto das sacolas plásticas após sua utilização.

No entanto, por serem muito utilizadas para o acondicionamento de lixo, as sacolas plásticas deixam de estar disponíveis na cadeia de reciclagem mecânica. Por essa razão, a indústria brasileira, a exemplo do que fizeram alguns países europeus, Japão e EUA, vem fomentando a reciclagem energética, processo de geração de energia por tratamento térmico do lixo, como parte importante da solução do problema do lixo urbano não reciclável. Nesse processo utiliza-se o lixo urbano como combustível, recuperando seu potencial energético; reduz-se o volume do lixo e os efeitos nocivos da biodegradação do lixo orgânico nos aterros; decompõe-se termicamente o lixo e filtra os gases poluentes produzidos no processo, atendendo rigorosos limites de emissão exigidos pelas normas ambientais e liberando na atmosfera basicamente vapor de água e gás carbônico. Destaca-se que para esse tipo de processo apenas os resíduos poliméricos não recicláveis e a matéria orgânica devem ser incinerados ${ }^{[2]}$.

O potencial energético do plástico é maior que da madeira e equivalente ao óleo diesel ${ }^{[21]}$. Segundo divulgação da Plastivida, uma sacolinha tem energia suficiente para manter uma lâmpada de $60 \mathrm{~W}$ acesa por 10 minutos $^{[2]}$. O Brasil possui apenas uma unidade piloto de usina de reciclagem energética, a Usina Verde (www. usinaverde.com.br), louvável projeto da iniciativa privada no Rio de Janeiro.

Recentemente, um estudo comparativo de análise da ecoeficiência entre incineração com recuperação de energia e disposição em aterros, como técnicas de tratamento ou disposição do resíduo sólido urbano (RSU) foi realizado no $\mathrm{IPEN}^{[22]}$. Os resultados obtidos por esse trabalho apontaram a incineração com recuperação de energia como uma alternativa melhor que a disposição em aterros com $65 \%$ de eficiência na coleta e tratamento do biogás (flares enclausurados), sendo a etapa de recuperação de energia fundamental para esse resultado.

\section{Alternativas de Substituição}

\section{Sacolas reutilizáveis}

Dentre as alternativas apontadas, vários estudos de análise de ciclo de vida (ACV) e/ou impacto ambiental ${ }^{[23-27]}$ concordam que a opção mais sustentável é a utilização de sacolas reutilizáveis. Essa alternativa, em termos de consumo energético na produção e uso, tem um ganho associado enorme, variando o gasto energético de $120 \mathrm{~kJ}$ para as sacolas reutilizáveis a $1.344 \mathrm{~kJ}$ e $1.047 \mathrm{~kJ}$ para as sacolas de papel e plástico, respectivamente ${ }^{[28]}$. Essa opção pode ainda ser considerada economicamente viável, pois segundo pesquisa realizada pela $\mathrm{ACG}^{[17]}$ e por Nolan ITU ${ }^{[29]}$, uma sacola reutilizável substitui cerca de 125 sacolas de plásticos tradicionais e tem uma vida estimada entre 12 a 104 viagens (ou dois anos, considerando uma ida ao supermercado por semana). Outro benefício direto é a redução no consumo de matéria-prima.

É estimado que na Nova Zelândia, 33\% ou 1.320 .000 pessoas usam sacolas reutilizáveis, incluindo sacolas de PE espessas, sacolas de ráfia de $\mathrm{PP}$, sacolas de tecido de várias fontes e caixas de plástico rígido ou vime ${ }^{[17]}$. Essas sacolas reutilizáveis podem ser compradas ou recebidas como brindes da iniciativa privada em campanhas publicitárias ou de grupos ambientais.

Entre as opções de sacolas reutilizáveis, as sacolas de tecido feitas a partir de material reciclável são as que apresentam menor impacto entre todas as categorias ${ }^{[29]}$, desde que programas de reciclagem sejam incentivados para reduzir seus impactos. No caso das sacolas de tecido de fonte renovável, como linho, algodão e juta, seus impactos estão relacionados com a limpeza, uso de água, agentes de limpeza, energia e pesticidas e fertilizantes utilizados na agroindústria. Além disso, a implantação de sistemas de reciclagem dessas sacolas no final de sua vida útil é relativamente mais difícil. Assim, para uma redução do impacto ambiental geral, as sacolas que combinam "redução de uso de recursos, longevidade e reciclagem" são as melhores opções ${ }^{[25-26,29]}$. James e Grant ${ }^{[27]}$ foram um pouco mais específicos e concluíram que "sacolas reutilizáveis a base de polímeros tem impactos ambientais menores que todos os tipos de sacolas de uso único".

\section{Sacolas de biopolímeros}

Já com relação às sacolas de plásticos biodegradáveis, biopolímeros e bioplásticos, comparadas às de plástico convencional, existem divergências na literatura. No entanto, de uma forma geral, tem-se que materiais de fonte renovável são considerados ambientalmente sustentáveis e se dispostos apropriadamente podem reduzir seu impacto durante a disposição final. Desse modo, há previsão que os biopolímeros de fontes renováveis substituirão os materiais de fontes não-renováveis em grande escala e em alguns 
casos já são economicamente viáveis ${ }^{[1]}$. Essa imagem positiva das sacolas de plásticos biodegradáveis em relação às sacolas convencionais de PE segue a mesma tendência das fibras naturais e do papel convencional, que são biodegradáveis e provenientes de fonte renovável.

Como opções de biopolímeros comercialmente disponíveis (www.biopolymer.net) tem-se, por exemplo: polímeros à base de amido da Mater-Bi ${ }^{\mathrm{TM}}$ (www.materbi.com), podendo ser provenientes de milho, batata, mandioca e trigo; poli(ácido lático) da NatureWorks ${ }^{\mathrm{TM}}$ (http://www.cargilldow.com), Bioska ${ }^{\mathrm{TM}}$ (www. plastiroll.fi), Bioplast ${ }^{\mathrm{TM}}$ (www.biotec.de), Solanyl ${ }^{\mathrm{TM}} \quad$ (www. biopolymer.net), Potatopac ${ }^{\mathrm{TM}}$ (www.potatoplates.com), Greenfil ${ }^{\mathrm{TM}}$ (www.greenlightint.co.uk), Eco-Foam ${ }^{\mathrm{TM}}$ (www.eco-foam.com) e polietileno verde (www.braskem.com.br/plasticoverde). Apesar do amido ter grande potencial, ser abundante e barato, tendo produção anual em torno de 15 milhões de toneladas na Europa ${ }^{[30]}$, normalmente é comercializado na forma de blendas devido sua natureza hidrofílica e frágil ${ }^{[31]}$. Nesses casos, o material pode não ser totalmente biodegradável, observando-se apenas sua fragmentação.

Assim, antes dos biopolímeros substituírem os plásticos convencionais, esses materiais devem superar seus desafios relacionados ao desempenho, processabilidade e custo. A redução de custo é esperada pelo aumento na produção em escala, a qual no momento é menor que $0,1 \%$ daquela dos polímeros derivados do petróleo ${ }^{[32]}$. Além disso, o uso de sacolas de plástico biodegradável não pode impactar nas atividades de reciclagem convencional, pois resultaria em impactos significativos nesse setor industrial e também, em impactos sócio-econômicos dada a dádiva de benefícios que essa atividade possui. Sua sustentabilidade depende ainda de rotas de disposição e de sistemas de recuperação apropriados, além de infra-estrutura de processamento e entendimento dos tipos e resíduos da degradação ${ }^{[33]}$.

Entre as controvérsias existentes nos estudos de análise de ciclo de vida (ACV), pode-se destacar o estudo realizado por Blengini ${ }^{[23]}$, voltado para análise do distrito de Asti (Itália), que indica uma redução em torno de $40 \%$ no consumo energético e de $29 \%$ no impacto ambiental pela substituição das sacolas de plástico pelas sacolas de bioplásticos, quando há uma política de gerenciamento dos resíduos de sacolas de bioplásticos vinculada a compostagem dos resíduos orgânicos com aplicação do composto como fertilizante. Por outro lado, estudos realizados pelo Instituto de Pesquisas Energéticas e Ambientais da Alemanha ${ }^{[34-35]}$ concluíram que os plásticos provenientes do petróleo, especialmente se recicláveis, tem impactos ambientais por ACV menores que os plásticos compostáveis. No caso dos bioplásticos, eles atribuíram o pior desempenho ambiental em função do processo de produção e extração da matéria-prima agroindustrial ${ }^{[34-35]}$. Ren e Patel ${ }^{[36]}$ obtiveram um resultado semelhante com base no gasto energético da síntese de insumos químicos a partir da biomassa ser muito superior aos métodos convencionais de síntese a partir do petróleo. Esse resultado foi obtido inclusive para a síntese do etileno, a partir do etanol da cana-de-açúcar. Tabone et al. ${ }^{[37]}$ avaliou os impactos ambientais provenientes da extração e síntese dos biopolímeros, sem incluir etapas de uso e fim de vida dos diferentes polímeros, e evidenciaram também que os biopolímeros apresentam maiores impactos na eutrofização, saúde humana e ecotoxicidade que os plásticos convencionais devido às atividades agrícolas e aos processos de fermentação e/ou químicos envolvidos na sua síntese. No entanto, qualquer que seja o estudo já realizado, não há questionamentos sobre os benefícios das rotas envolvendo biomassa, com relação à quantidade de emissão de gases do efeito estufa poupada.
Porém, mesmo num cenário que considere os materiais biodegradáveis e/ou degradáveis como uma das soluções mais promissoras para o problema das sacolas plásticas ${ }^{[38]}$, a responsabilidade do produtor, transformador, usuário e consumidor desses materiais são as mesmas daquelas dos plásticos convencionais. As sacolas de plástico biodegradável não irão desaparecer rapidamente quando dispostas no meio ambiente e seu impacto no ambiente marinho depende de quanto tempo ela flutua sobre a água, sendo no mínimo 01 dia o tempo necessário para que sacolas de amido com biopoliéster, poli(ácido lático) (PLA) e papel afundem. De acordo com documento elaborado por ExcelPlas Austrália, Centro de Design da Universidade RMIT (Instituto Real de Tecnologia de Melbourne) e Nolan-ITU foi estimado que as sacolas plásticas convencionais demoram 6 meses para afundar no ambiente marinho, considerando que esse período é suficiente para o crescimento de algas em sua superfície e/ou retorno do resíduo para a $\operatorname{costa}^{[27,38]}$. Alternativas como blendas de plástico biodegradável com polietileno demorariam o mesmo intervalo de tempo e o potencial de redução desse tempo foi estimado em $50 \%$ no caso de sacolas com aditivo oxibiodegradável, ou seja, 03 meses $^{[27,38]}$.

Assim, se a postura de disposição irregular do lixo não for corrigida, o uso de sacolas de blendas de plástico biodegradável com polietileno pode até resultar num potencial aumento do impacto das sacolas de plástico no meio ambiente. Por essa razão e outras associadas à poluição do solo e contaminação dos processos de reciclagem, por exemplo, é que pesquisas sugerem que os plásticos biodegradáveis têm os mesmos impactos das sacolas tradicionais de polietileno ${ }^{[33]}$ e que eles não contribuem para reduzir a poluição visual e nem os impactos no ambiente marinho das sacolas plásticas ${ }^{[17]}$. Com relação à contaminação do solo, a preocupação reside nos subprodutos de sua biodegradação como, por exemplo, presença de outros polímeros, aditivos, cargas, colorantes, metais, oligômeros, que não são necessariamente absorvidos pelos ciclos ambientais e processos naturais, deixando resíduos e produtos da degradação no meio ambiente como em solo, rios, lençóis freáticos e na atmosfera, com impactos ainda desconhecidos.

Portanto, mesmo sendo degradável ou biodegradável, o resíduo requer coleta e local adequado para disposição final. A responsabilidade do consumidor, produtor e poder público não são menores. Os conceitos e campanhas de educação como: jogar o lixo no lixo; separar resíduo reciclável; destinar para reciclagem e consumo sustentável tem a mesma importância e validade qualquer que seja a solução adotada.

Em termos de gerenciamento do resíduo sólido, as embalagens biodegradáveis são apropriadas para os sistemas de compostagem domésticos e comerciais. Dentro do conceito de responsabilidade do produtor, a compostagem é considerada uma das formas de recuperação aceita pela legislação da comunidade européia com relação ao resíduo de embalagens biodegradáveis ${ }^{[30]}$. Metas para 2020 de redução da ordem de $35 \%$ do resíduo municipal biodegradável (RMB) que vai para aterro foram estabelecidas pelo artigo 5 da diretiva sobre aterros 99/31/EC, tendo como referência o ano de 1995. Essa meta é para reduzir os impactos ambientais negativos associados com a produção de chorume e metano ${ }^{[39]}$. Como resultado houve a proliferação de pontos de coleta seletiva com foco em RMB.

Em Kassel, na Alemanha, em 2001 embalagens de plástico biodegradável foram introduzidas no mercado varejista da cidade. $\mathrm{O}$ objetivo era gerenciar junto aos domicílios um procedimento de separação das embalagens biodegradáveis com o lixo orgânico para produzir composto. Esse procedimento exigiu uma ação preliminar junto ao público para orientação sobre polímeros biodegradáveis, sua rotulagem, identificação, separação e $\operatorname{coleta}^{[40]}$. O composto 
gerado de forma controlada e estabelecendo uma proporção de apenas $1 \%$ de embalagens de biopolímeros no resíduo orgânico teve qualidade comprovada similarmente ao composto tradicional ${ }^{[41]}$. Um dos fatores de sucesso da iniciativa foi devido aos baixos índices de contaminação do lixo orgânico, resultado da ação da população que demonstrou $82 \%$ de eficiência na separação e esse município atingiu $90 \%$ de substituição das sacolas convencionais pelas compostáveis. Outro exemplo é o distrito de Asti ${ }^{[23]}$, cuja gestão do lixo foi direcionada para a fração orgânica, já que $37 \%$ do lixo consiste em restos de alimentos e resíduo de poda de árvores. No entanto, preocupações com relação aos subprodutos da biodegradação desses plásticos ainda existem.

$\mathrm{Na}$ Inglaterra, a legislação impõe restrições relacionadas à compostagem simples de resíduo orgânico doméstico e, por associação, embalagens plásticas biodegradáveis, pois a temperatura pode não aumentar o suficiente para matar os patógenos ${ }^{[30]}$. Nesses casos, é exigido o uso do sistema de compostagem em reatores de digestão anaeróbia, seguindo exigências específicas de manuseio, temperatura e tempo de residência para atender aos critérios estabelecidos pelo Regulamento de Subproduto Animal (Animal By-Product Regulation). Com isso, a compostagem tem perdido competitividade econômica frente a outras alternativas, como, por exemplo, disposição em aterros.

Especificamente, no Brasil, a compostagem poderia ser viável porque, segundo dados da Abrelpe (Associação Brasileira de Empresas de Limpeza Pública e Resíduos Especiais), cerca de $57 \%$ do RSU no Brasil são de materiais orgânicos. Apesar disso, a revalorização dos biopolímeros pós-consumo por essa via ainda é incipiente e não é uma alternativa de gestão implantada no país. Esse tipo de resíduo, os materiais orgânicos, se for disposto em aterros e não for submetido a um processo de biodegradação adequado, geram impactos negativos tais como: emissão de metano, chorume, odores e proliferação de doenças ${ }^{[2]}$.

Por outro lado, o uso de composto orgânico como fertilizante, aumenta a concentração de carbono no solo e pode ser uma forma de seqüestrar carbono ${ }^{[42]}$. De acordo com Linzner e Mostbauer ${ }^{[43]}$, o potencial de seqüestro de carbono pode variar de 133 a $213 \mathrm{~kg}$ de $\mathrm{CO}_{2}$ equivalente por tonelada de composto maturado. Um valor de $173 \mathrm{~kg}$ de $\mathrm{CO}_{2}$ equivalente por tonelada de composto maturado foi utilizado no trabalho de Benglini ${ }^{[23]}$ para a fase de conversão do composto maturado em fertilizante sintético a base de N, P e K. Esse valor estimado por tonelada de bioresíduo tem potencial de seqüestro de carbono de $48 \mathrm{~kg}$ de $\mathrm{CO}_{2}$ equivalente, considerando a média italiana de conversão de bioresíduo em composto maturado em torno de 0,28 t de composto maturado por ton de bioresíduo. Em termos de valor mássico de quantidade de produção evitada de fertilizante, tem-se, segundo esse autor ${ }^{[23]}$, que a compostagem de uma ton de bioresíduo evita a produção de $8,4 \mathrm{~kg}$ de fertilizante sintético a base de N, P e K. Além disso, a compostagem de resíduos orgânicos de cozinha e jardins pode melhorar a eficiência dos processos de incineração de matéria orgânica e de resíduos plásticos não recicláveis com recuperação de energia ${ }^{[35]}$, pois esses resíduos orgânicos possuem altos teores de umidade.

No caso dos biopolímeros, provenientes de fontes renováveis, como citado por Blengini ${ }^{[23]}$, do ponto de vista do ciclo do carbono, o carbono biogênico é considerado como sendo equivalente ao $\mathrm{CO}_{2}$ absorvido durante o crescimento da planta. Assim, no caso do processo de biodegradação em condições aeróbicas que transforma o lixo orgânico em água, húmus e gás carbônico, a emissão de $\mathrm{CO}_{2}$ pode ser considerada nula. Por outro lado, no caso do processo de biodegradação em condições anaeróbicas há formação de metano $\left(\mathrm{CH}_{4}\right)$ ao invés de $\mathrm{CO}_{2}$ e a emissão de gases do efeito estufa deixa de ser nula, pois o potencial de contribuição do metano para o aquecimento global é 24 vezes superior ao do $\mathrm{CO}_{2}{ }^{[44]}$. Logo, a utilização de embalagens biodegradáveis que vai terminar nos aterros e lixões, ou seja, na ausência de oxigênio, pode significar, na prática, mais impacto ao meio ambiente que as demais alternativas. O aproveitamento desse gás como fonte de energia pode ser uma opção sustentável. Assim, a digestão anaeróbica com recuperação do biogás tem apresentado melhor desempenho que a compostagem em termos de mudanças climáticas e demanda energética ${ }^{[45]}$, já que economiza tempo e recursos para produção de fertilizantes e energia.

Porém, na Nova Zelândia, o uso de metano na produção de energia é limitado devido às alterações exigidas nos aterros envolverem custos significativos. Independentemente, o investimento em infra-estrutura para a compostagem, digestão anaeróbia com aproveitamento energético e/ou de aproveitamento do biogás em aterros é importante para contornar o problema de gerenciamento do metano oriundo de materiais biodegradáveis em aterros. Este é um dos maiores problemas de gestão do lixo orgânico dada a sua ação prolongada, que é estimada em mais de 100 anos após fechamento do aterro ${ }^{[17]}$. Logo, para os biopolímeros, a disposição em aterros é a pior opção em função dos impactos relacionados à geração de metano, chorume, vetores de doenças, liberação de odores, entre outros. Para a engenharia sanitária, a disposição de materiais estáveis em aterros facilita sua gestão. Na Alemanha o número de aterros que aceitam apenas lixo inerte e que tem o lixo orgânico e degradável bioestabilizados antes de serem aterrados está aumentando ${ }^{[46]}$. Esses aterros são denominados de baixa emissão e requerem menos controle e engenharia que os demais.

Desde que os plásticos biodegradáveis são projetados para degradar após o uso, eles geralmente são considerados inapropriados para os processos convencionais de reciclagem. No entanto, há controvérsias, pois os processos de biodegradação dependem do tipo de polímero e das condições de descarte, podendo ser rápido ou lento ${ }^{[1,47]}$. Portanto, dada à escassez de informações científicas, os processos de reciclagem mecânica e química de biopolímeros não podem ser classificados como benéficos ou não, apesar de terem uma tendência a ter o melhor desempenho ambiental ${ }^{[45]}$. Diversas fontes relatadas por Michaud et al. ${ }^{[45]}$ confirmam que a compostagem em digestor anaeróbico com aproveitamento do biogás ${ }^{[45]}$ é a opção mais adequada para gestão de resíduos de polímeros biodegradáveis. Já a compostagem simples frente a incineração com recuperação energética é considerada ineficiente em termos de demanda energética e esgotamento dos recursos naturais. Por outro lado, no quesito aquecimento global, a comparação entre compostagem e incineração com recuperação energética depende dos valores das taxas de degradação dos resíduos. De acordo com Michaud et al. ${ }^{[45]}$, a incineração pode ter um impacto no aquecimento global menor que a compostagem, se as taxas de degradação forem altas (acima de 90\%). Caso as taxas de degradação dos resíduos sejam baixas (na faixa de 30 a $50 \%$ ), a compostagem passa a ser a melhor opção, considerando nos cálculos os valores de carbono biogênico da fonte do resíduo biodegradável, parâmetro também determinante dos cálculos de impacto no aquecimento global. Por outro lado, a compostagem, independente da taxa de degradação, pode alcançar um menor impacto no aquecimento global em relação a essas opções, se a quantidade de emissão evitada com a produção de fertilizantes for inserida na avaliação. Independentemente, na avaliação de impactos no aquecimento global, a digestão anaeróbia com aproveitamento de biogás é considerada a melhor opção ${ }^{[45]}$.

Nesse contexto, a utilização de biopolímeros não-biodegradáveis e recicláveis pode ser uma opção sustentável nas próximas décadas em função da previsão de redução de preço dos processos de síntese de insumos químicos a partir da biomassa. $\mathrm{O}$ polietileno 
verde desenvolvido pela Braskem, que já tem uma demanda três vezes superior à capacidade de produção da unidade inaugurada em $2010^{[48]}$, é um sinal dessa mudança, considerando o atendimento às metas de redução de emissão de gases do efeito estufa (GEE) pré-fixadas por inúmeras companhias ao redor do mundo ${ }^{[49]}$. Porém, para uso em sacolas plásticas, essa opção deve ser avaliada levando em conta também os impactos que a monocultura da cana de açúcar poderá causar aos ecossistemas existentes na região.

\section{Sacolas de plásticos com aditivo oxibiodegradável}

Os plásticos com aditivos oxibiodegradáveis são plásticos convencionais aditivados com a função de acelerar o seu processo de degradação. Esses aditivos possuem metais de transição tais como cobalto $(\mathrm{Co})$, ferro $(\mathrm{Fe})$, manganês $(\mathrm{Mn})$ ou níquel $(\mathrm{Ni})$, que agem no mecanismo de degradação do polímero como catalisadores ou, na linguagem comum, como "aceleradores"[35,50,51]. Esses plásticos são denominados como ambientalmente degradáveis, pois se degradam pela ação de agentes naturais como água, radiação ultra-violeta e oxigênio ${ }^{[17]}$.

Há várias polêmicas e discussões relacionadas a esse tipo de plástico. A seguir são relatados alguns esclarecimentos prestados pelo inventor Gerald Scott, em entrevista publicada na Bioplastics Magazine ${ }^{[35]}$. Segundo Scott ${ }^{[35]}$, os plásticos oxibiodegradáveis não foram projetados para a compostagem, nem para digestão anaeróbia e nem para a degradação no fundo dos aterros. Eles foram projetados para degradarem e, depois, biodegradarem na presença de oxigênio, retornando ao ciclo biológico do carbono. Eles são especificados para serem completamente bioassimilados pelos microorganismos, porém num tempo maior que aquele requerido para compostagem, de 180 dias, e menor que aquele do lixo plástico descartado na natureza, de muitas décadas. Folhas, palhas e gravetos, podem demorar 10 anos ou mais para se biodegradarem na natureza, dependendo da quantidade de calor e luz que estão expostos. No caso dos plásticos derivados do petróleo é previsto, com base em estudos realizados com n-alcanos lineares de até $500 \mathrm{Da}^{[52]}$, que os mesmos podem ser absorvidos pelos microorganismos após degradarem e se fragmentarem. A diferença é que os aditivos oxibiodegradáveis aceleram esse processo.

A partir disso, foi criada a definição da classe de plásticos ambientalmente degradáveis (Environmentally Degradable Polymers), que consiste em um grande grupo de materiais poliméricos sintéticos e naturais que sofrem alteração química sob a influência de fatores ambientais ${ }^{[53]}$. Esses fenômenos devem ocorrer em duas fases: a primeira é a deterioração das propriedades físicas, e a segunda é a conversão dos fragmentos plásticos em $\mathrm{CO}_{2}$ e água, em condições aeróbicas, ou em $\mathrm{CO}_{2}$ e $\mathrm{CH}_{4}$, em condições anaeróbicas.

Além disso, os efeitos fitotóxicos e conceito de plástico compostável dos plásticos oxibiodegradáveis estão estabelecidos em norma específica para essa classe de material plástico (ASTM D 6954-04 "Exposing \& Testing Plastics that Degrade in the Environment by a Combination of Oxidation \& Biodegradation") ${ }^{[35]}$. Complementarmente, tem-se a norma BS EN ISO 13432:2000 "Packaging. Requirements for packaging recoverable through composting and biodegradation. Test scheme and evaluation criteria for the final acceptance of packaging", que estabelece o limite aceitável de teor de níquel no composto.

Em contrapartida, não há estudos sistematizados sobre o limite a partir do qual a inclusão de plásticos com aditivo oxibiodegradável interfere no processo de reciclagem dos plásticos convencionais. Porém, Gerald Scott, em sua entrevista à Bioplastics Magazine ${ }^{[35]}$, cita que as sacolas de plástico oxibiodegradável são recomendadas para serem formuladas para ter uma vida útil de no mínimo
18 meses. Nesse intervalo, elas podem ser recicladas, desde que sejam adicionados agentes estabilizantes que neutralizem o efeito do agente pró-degradante presente. Por outro lado, segundo Scott, se os plásticos oxibiodegradáveis forem dispostos nos aterros sanitários, eles só irão se desintegrar e biodegradar parcialmente, se estiverem na superfície ou próximo a ela. Caso contrário, irão permanecer inertes, ocupando espaço como os plásticos convencionais e sem aproveitamento do potencial energético do material, dada a ausência de oxigênio nessas condições.

\section{Sacolas de papel}

De acordo com todos os comentários anteriores, pode-se considerar que há um consenso acadêmico e científico que simplesmente ser biodegradável não é solução. O público e a cadeia produtiva ainda não são unânimes nessa questão ${ }^{[17]}$, pois, tradicionalmente, as sacolas de papel foram apresentadas como ambientalmente corretas, quando comparadas com as sacolas de plástico. Apesar dessa associação positiva com relação às sacolas de papel, estudos recentes mostram que elas são igualmente ou mais prejudiciais ao meio ambiente que as sacolas de plástico ${ }^{[25-29,54-55]}$.

Seguindo a mesma tendência têm-se os estudos de análise de ciclo de vida realizados por Nolan ITU $^{[29]}$, McCarthy ${ }^{[56]}$ e Scott ${ }^{[57]}$. Eles também sugerem que embalagens de papel possuem impactos energéticos e de contaminação ambiental maiores que as poliolefinas, devido aos efluentes gerados nos processos de polpação e branqueamento da produção do papel e as emissões gasosas da produção e distribuição do papel. Além disso, se disposto no aterro, o papel tem taxa de degradação maior que o plástico e portanto, maior impacto no aquecimento global que as embalagens plásticas.

$\mathrm{O}$ estudo realizado por Tough ${ }^{[17]}$ também concluiu que tanto as sacolas biodegradáveis, quanto as de papel tem mais impactos danosos ao meio ambiente que as sacolas de plástico convencionais. Os impactos associados e avaliados nesse estudo foram aqueles relacionados ao uso de energia, água, poluição da água; poluição do ar; produção de resíduos sólidos e disposição irregular.

Esse tipo de conclusão distingue daquela do público, pois o mesmo não considera o corte de árvores, o uso de agentes químicos como, por exemplo, hidróxido de sódio e peróxido de hidrogênio, e a energia usada para fazer e reciclar as sacolas de pape ${ }^{[17,26]}$. Inclusive, as emissões de carbono e consumo de combustível no transporte do papel são maiores que aquelas do plástico devido seu maior peso, isto é, maior densidade.

Por outro lado, áreas de reflorestamento são fixadoras de carbono e consistem numa ferramenta para ganhar créditos de carbono. Entretanto, o subseqüente corte das árvores para fazer papel remove o agente fixador de carbono e contribui para a degradação da terra, danos no ecossistema, uso de combustível e emissões de carbono. Além disso, árvores de áreas reflorestadas apresentam impactos decorrentes de monocultura e de controle da terra, uso de fertilizantes e água.

Até mesmo na disposição final, se as sacolas de papel forem dispostas em aterros geram metano, gás do efeito estufa ${ }^{[25-27,29,55]}$. Estudos mais recentes sugerem que a quantidade de energia consumida na produção de sacolas de papel e plástico são equivalentes ${ }^{[25]}$. Entretanto, a produção, uso e disposição das sacolas de papel consomem 3 vezes mais água, produzem $90 \%$ mais gases do efeito estufa; 12 vezes mais nitratos e fosfatos, agentes poluidores da água; $80 \%$ mais emissões de óxidos de nitrogênio e dióxidos de enxofre; e $80 \%$ mais resíduos sólidos que as sacolas de plástico convencionais ${ }^{[25]}$.

De acordo com as alternativas (sacolas de papel, plástico convencional ou biodegradável e sacolas reutilizáveis) estudadas pela Allen Consulting Group (ACG) $)^{[58]}$, a produção do papel foi 
a que apresentou ainda maior emissão de gases do efeito estufa, estimado em 30,2 kg/ano de $\mathrm{CO}_{2}$ equivalente. No caso das sacolas reutilizáveis, esse impacto ficou em $2 \mathrm{~kg} /$ ano de $\mathrm{CO}_{2}$ equivalente. Já as atividades de reciclagem do papel, de acordo com a WRAP, reduzem a emissão de $\mathrm{CO}_{2}$ por um fator de $0,8 \mathrm{t}$ de papel reciclado por tonelada equivalente de emissão de $\mathrm{CO}_{2}^{[59]}$. Efeitos da eutrofização (super-abundância de plantas aquáticas que entram em decomposição, causando a queda da concentração de oxigênio e afetando as condições de vida dos peixes) por fosfato pelas sacolas de papel também não podem ser negligenciados ${ }^{[58]}$. Portanto, é a falta de conscientização e conhecimento desses impactos por parte dos usuários dos diferentes segmentos da sociedade que ainda faz a hipótese do uso de sacolas de papel uma opção melhor que as sacolas de plástico.

Entre as alternativas para gerenciamento do resíduo de papel tem-se que a disposição de papel e papelão em aterros é a opção menos favorável, considerando o potencial de mudança climática e demanda energética. Já as diferenças relacionadas aos impactos dos processos de recuperação energética e reciclagem mecânica do papel são pequenas ${ }^{[45]}$. Porém, de acordo com estudo realizado por Michaud et al. ${ }^{[45]}$, a reciclagem mecânica é preferível à incineração para todas as categorias de impacto. Entre as vantagens do processo de reciclagem mecânica destaca-se: a não utilização das etapas convencionais de branqueamento do papel virgem ${ }^{[60]} \mathrm{e}$ uma economia significativa na demanda de água. No entanto, com a melhoria da eficiência energética dos processos de incineração e sua utilização para substituir o uso de combustíveis, a exemplo da Inglaterra, a comparação pode ser alterada especialmente em relação ao potencial de mudanças climáticas e esgotamento dos recursos naturais. $\mathrm{O}$ balanço entre a energia usada no processo de reciclagem mecânica do papel pela energia economizada na produção de material primário não é significativa. Além disso, geralmente, o papel reciclado é usado para a produção de papelão e não, produtos de alta qualidade, tais como papel de escritório ${ }^{[45]}$.

Novas tecnologias como pirólise, gaseificação, digestão anaeróbia e compostagem não foram avaliadas ${ }^{[45]}$. Já as rotas biotecnológicas que promovam a redução dos impactos ambientais, por exemplo, com o uso de enzimas como agente de branqueamento, e aumentem a eficiência dos processos de produção do papel com plantas geneticamente modificadas para facilitar a separação da lignina da celulose, ainda não podem ser consideradas sustentáveis, pois são caras e/ou improdutivas ${ }^{[1]}$.

\section{Sacolas de papel sintético de plástico reciclado}

Uma alternativa inovadora que vai ao encontro do requerido para as melhores opções, que combinam "redução de uso de recursos, longevidade e reciclagem" ${ }^{225-26,29]}$, seriam sacolas e caixas reutilizáveis feitas de papel sintético de plástico reciclado. A condição de serem produtos reutilizáveis advém do fato de que, na concepção do papel de plástico reciclado, foi proposto desenvolver uma tecnologia sustentável para produzir um novo material a partir de plástico de resíduo urbano que fosse de alta qualidade, alto valor agregado, e que pudesse ser utilizado na fabricação de bens mais duráveis, ao invés de produtos rapidamente descartados. Esse papel sintético ecológico foi desenvolvido pelo grupo de pesquisa de Sati Manrich $^{[21,61-66]}$, do DEMa, no laboratório de reciclagem 3R-nrr da UFSCar. Os testes em planta piloto foram realizados em parceria com a empresa Vitopel, que se responsabilizou pela industrialização da tecnologia para produção em escala. A empresa passou a produzir o papel sintético ecológico Vitopaper ${ }^{\circledR}$, o qual é atualmente a única opção comercial dessa inovação ${ }^{[61,67-69]}$.

O novo material é leve (baixa densidade) e resistente, não molha e não rasga, apresenta alta qualidade de escrita e impressão e aspecto visual até superior ao do papel-cuchê, de forma que associa as melhores características dos plásticos com as do papel convencional, mesmo tendo em sua composição até $85 \%$ em peso de plástico recuperado do lixo e reciclado mecanicamente ${ }^{[21,61,67,70]}$. Por se tratar de um lançamento recente, seu preço ainda relativamente alto pode ser um fator negativo para o papel sintético ser uma opção para substituir os plásticos convencionais. O aumento da demanda com a familiarização, conhecimento e aceitação pelo mercado, com o conseqüente aumento da produção em escala, certamente tornará o preço desse produto competitivo ${ }^{[68,69]}$. Associado a isso, se levarmos em conta outros fatores para avaliação, produtos feitos com esse material poderão ser considerados como uma alternativa viável para substituição, mesmo que parcial, das sacolas de papel convencional de celulose e de plásticos convencionais ${ }^{[21,61]}$.

Por exemplo, caixinhas e sacolas reutilizáveis de papel sintético ecológico seriam produzidas com menor consumo de recursos naturais esgotáveis e de energia do que as de plástico convencional porque a matéria-prima base é plástico pós-consumo reciclado e a reciclagem mecânica utiliza 50\% menos energia do que o processo primário de fabricação de plástico. O papel sintético reduz o impacto ambiental, comparativamente aos demais materiais citados, na medida em que retira ou evita que sejam descartados no meio ambiente até $850 \mathrm{~kg}$ de lixo plástico para cada tonelada produzida desse papel, sendo que quantidades equivalentes de matérias-primas virgens deixam de ser consumidas ${ }^{[21,61-62,67-69]}$.

Também, como não são incluídas fibras de celulose em sua composição, o papel sintético ecológico não necessita de corte de árvores e não utiliza de substâncias potencialmente tóxicas ou poluentes em seu processo de fabricação. Somado a tudo isso, as caixinhas e sacolas feitas com esse material são recicláveis com processos de reciclagem mecânica iguais aos atualmente utilizados na reciclagem das sacolas plásticas, além de serem compatíveis em misturas, em determinadas proporções, com sacolas e outros produtos de plásticos convencionais. Os resíduos de papel sintético reciclados podem voltar a compor novas sacolas e caixas, fechando completamente seu ciclo de vida, ou compor novos produtos como livros, manuais, catálogos, cartilhas, revistas, ou ainda outros produtos plásticos fabricados por diferentes processos de moldagem ${ }^{[21,61-63,67,70]}$. Evidentemente que as etapas de coleta, preferencialmente seletiva, e de separação dos outros materiais são inevitáveis e importantes para uma reciclagem efetiva dos resíduos de papel sintético de plástico reciclado.

\section{Gestão dos resíduos de sacolas}

Como pode ser constatado, independentemente da solução adotada, ela deve estar intrinsecamente associada à política de gerenciamento do resíduo sólido urbano. Idealmente, as alternativas que incluem como estratégia a reciclagem mecânica podem ter, em termos de gerenciamento de resíduos, o melhor desempenho ambiental.

De acordo com estudo de análise de ciclo de vida realizado por Michaud et al. ${ }^{[45]}$, a reciclagem mecânica foi considerada a melhor alternativa para gerenciamento do lixo, considerando impactos relacionados às mudanças climáticas, consumo de recursos naturais e demanda de energia. No entanto, os benefícios da reciclagem são válidos considerando materiais reciclados de valor agregado equivalente ao virgem, pois reside principalmente na economia de crédito de carbono por evitar a produção de material virgem. Para atingir esse requisito, sistemas de coleta seletiva têm um papel importante. Com base nesse estudo, a reciclagem mecânica tem sido favorecida na Inglaterra como estratégia para redução das emissões de carbono. No entanto, dependendo das dificuldades encontradas na coleta, identificação, separação e transporte, outras alternativas 
podem se tornar mais convenientes ${ }^{[30]}$, visto que aproximadamente $2 / 3$ do custo total do reciclado advém das etapas de coleta e separação dos plásticos ${ }^{[71]}$.

Nos casos representando substituição parcial do material virgem pelo reciclado, dependendo do contexto global, a reciclagem também pode não ser a melhor alternativa para gestão do resíduo sólido. Outra opção seria a incineração com recuperação energética que, por sua vez, tem alto impacto nas mudanças climáticas. Dados de ACV de pirólise ainda são insuficientes para uma conclusão mais precisa com relação a essa alternativa de gestão do resíduo sólido urbano. Há ainda a opção de reciclagem química para recuperar os insumos originais. No entanto, a maioria das rotas de reciclagem química ainda precisa alcançar a viabilidade econômica. Independentemente, a disposição em aterro aparece, na maioria dos casos, como a pior das opções ${ }^{[45]}$.

A utilização de material reciclado com retorno ao seu ciclo de vida, além de retirar do meio ambiente uma boa parte de resíduos plásticos derivados do petróleo, que levariam mais de 300 anos para serem degradados, diminui o custo final do produto e gera inúmeras oportunidades de empregos diretos e indiretos para pessoas socialmente excluídas. A reciclagem vai ainda ao encontro do conceito de "loop society"[72], no qual a sociedade usa sempre os mesmos materiais sem a necessidade de novas fontes.

A responsabilidade ambiental e social dessa atividade é grande e impacta para um melhor equilíbrio ecológico e econômico na região em que atua. Assim, a reciclagem pós-consumo é o modelo que melhor se adapta à situação social do Brasil, pois gera emprego em toda a cadeia envolvida na coleta, separação e distribuição do país. Além disso, a indústria do plástico oferece um número considerável de empregos, principalmente, se for considerada toda a cadeia produtiva e de distribuição. Em termos de desenvolvimento sustentável, esse aspecto é muito importante por atender ao tripé: ambientalmente correto, socialmente justo e economicamente viável.

\section{Políticas e Iniciativas de Controle}

Com a conscientização do público sobre os impactos das sacolas plásticas, vários países, estados, cidades e distritos tem implementado planos de ação estratégica para reduzir os resíduos de sacolas plásticas e seus impactos ${ }^{[17,19]}$. As principais medidas tomadas referem-se à: proibição do uso de sacolas plásticas, com exceções; redução do consumo indiscriminado; incentivo à reutilização; melhorias na eficiência do sistema de limpeza urbana e infra-estrutura da destinação final do lixo; aumento do número de recipientes de lixo nas ruas; obrigatoriedade da reciclagem; obrigatoriedade do uso de sacolas degradáveis/biodegradáveis; obrigatoriedade do uso de sacolas reutilizáveis; especificação de espessura mínima para permitir a reutilização e evitar a utilização de sacolas múltiplas, isto é, uma dentro da outra ou várias sacolas para carregar pequenas quantidades de produtos; taxas sob comercialização; preço mínimo e máximo para venda; exigências relacionadas ao teor mínimo de reciclado; medidas de incentivo e obrigatoriedade da responsabilidade do produtor na forma de financiamento de iniciativas de limpeza do lixo irregular, suporte à coleta seletiva das sacolas plásticas, imposto sobre sacolas plásticas; medidas de incentivo aos consumidores para usarem sacolas reutilizáveis, favorecendo descontos, acumulação de pontos, doações a instituições; subsídio às sacolas reutilizáveis; campanhas informativas e educacionais; esquemas voluntários de recolhimento das sacolinhas pelos supermercados; entre outras ${ }^{[19]}$.

A tendência da legislação ambiental no mundo todo é tornar as empresas cada vez mais envolvidas e responsáveis por todo o ciclo de vida dos seus produtos. Isso representa não só a preocupação com o extrativismo e os resíduos, mas também com o destino de seus produtos após o uso e as consequiências geradas por eles no meio ambiente. A Irlanda foi o primeiro país a atuar nesse sentido. No ano de 2002 obteve num curto intervalo de tempo mais de $90 \%$ de redução no consumo de sacolas plásticas, com a taxação de imposto sobre as mesmas. Depois, apresentou um crescimento no consumo de sacolas plásticas em função da adaptação do consumidor ao tributo de $€ 0,15$, o que levou a aumentá-lo em $2007^{[17,19]}$. A Nova Zelândia seguiu um modelo de cobrança de impostos semelhante ao irlandês. Na Austrália, campanhas de redução voluntária resultaram em $34 \%$ de redução no consumo de sacolas plásticas num período de 3 anos (2002-2005) $)^{[73]}$. Nesse país, os impactos das sacolas plásticas no meio marinho ajudaram a concretizar as ações da comunidade para reduzir o consumo e descarte irregular das sacolas plásticas.

No Reino Unido, em 2008, foi implantada a lei sobre mudanças climáticas, a qual incluía a criação de um imposto para redução do uso de sacolas plásticas. Porém, poucos aderiram a meta de redução de $25 \%$ em um ano e tem-se o registro de iniciativas anteriores que buscaram aumentar a quantidade de material reciclado e reduzir o peso das sacolas. Nos estados Unidos, São Francisco foi a primeira cidade a proibir o uso de sacolas plásticas em 2007, sendo o uso de sacolas de papel, a opção adotada. A China é outro país, no qual a distribuição gratuita de sacolas plásticas já foi proibida.

No Brasil ainda não existe uma lei nacional vigente nesse sentido $^{[19]}$. Há um projeto de lei da câmara dos deputados (PL-612/2007) que promove a substituição das sacolas convencionais por biodegradáveis em todos os estabelecimentos comerciais do território brasileiro. Ações conjuntas voltadas para campanhas de conscientização ambiental entre o governo do estado de São Paulo e a Associação Paulista de Supermercados (APAS) foram realizadas em 2008. Também em 2008, foi iniciada a campanha nacional intitulada "Consumo consciente de embalagens" pelo Ministério do Meio Ambiente ${ }^{[19]}$.

Paralelamente, também foi lançado o Programa de Qualidade e Consumo Responsável de Sacolas Plásticas, liderado pela Plastivida, Instituto Sócio-Ambiental dos Plásticos, Instituto Nacional do Plástico (INP) e pela Associação Brasileira da Indústria de Embalagens Plásticas Flexíveis (Abief). O programa baseado no princípio dos 3 R's (redução do número de sacolas, reuso e reciclagem) visa a redução do uso das sacolas plásticas, por meio da melhoria da sua qualidade e da conscientização em relação ao consumo $^{[2]}$. Como conseqüência foi editada a norma ABNT 14.937 e criado um selo de identificação (Selo de Qualidade Abief-INP) com a meta de reduzir o consumo de sacolas plásticas em no mínimo $30 \%{ }^{[2]}$. Como resultado do primeiro ano desse programa houve uma redução de 10,5\% no número de sacolas fabricadas. Atualmente o Programa está implantado em cinco capitais: São Paulo (SP), Salvador (BA), Porto Alegre (RS), Goiás (GO) e Brasília (DF) ${ }^{[2]}$.

Entre outras iniciativas isoladas em estados e municípios destaca-se o Rio de Janeiro que proibiu o uso as sacolas plásticas dentro do prazo de um ano após sancionamento da Lei. Em Americana-SP, supermercados oferecem atendimento preferencial e produtos da cesta básica, por exemplo, como incentivo para quem opta pelo uso de outras alternativas às sacolas plásticas ${ }^{[74]}$.

No Chile, também não há legislação nacional vigente. Em 2008 a Ministra do Meio Ambiente lançou uma campanha que busca reduzir o uso de sacolas plásticas substituindo-as por sacolas de papel. Na Argentina há um projeto de lei nacional que proíbe o uso de sacolas de plástico convencional que deve ser progressivamente substituído por materiais degradáveis ou biodegradáveis. Em Buenos Aires e Mendonça, essa lei já está vigente com prazo de 12 a 24 meses para implantação ${ }^{[19]}$. 
No Uruguai já foi elaborado um plano estratégico para impulsionar o uso racional e sustentável das sacolas plásticas, tendo como metas $40 \%$ de redução do consumo médio por habitante, sua substituição nos casos possíveis e a promoção de sua reciclagem, com prazo para cumprimento das metas considerando o período de 2008 a $2015^{[19]}$. O plano se apóia em linhas estratégicas que buscam melhorar a gestão de resíduos sólidos urbanos com base nos 3 Rs, incentivar o uso de materiais degradáveis e conscientizar a população para o uso responsável e racional de sacolas plásticas, assim como a obrigatoriedade dos estabelecimentos comerciais de implementar ações que contribuam com as linhas estratégicas ${ }^{[19]}$. Um projeto de lei que proíbe o uso de sacolas plásticas e promove sua substituição por materiais ambientalmente degradáveis ou biodegradáveis também está em estudo. Em Montevidéu, uma taxa por embalagem ou sacola plástica já é cobrada dos fabricantes e importadores, desde início de 2009. A campanha de conscientização da população já tem seus resultados, pois em pesquisa realizada pela consultoria Equipos Mori, 74\% da população está disposta a usar menos sacolas plásticas; $71 \%$ está disposta a reutilizar as sacolas plásticas, evitando o consumo de novas sacolas; e 69\% da população está disposta a usar carrinho de feira para não usar sacolas plásticas ${ }^{[19]}$.

De acordo com esses exemplos, a ação voluntária pode ser uma ação de menor custo e tem capacidade de reduzir o consumo, como demonstrado na Austrália, mas não é capaz de atingir as metas e nem reduzir a disposição irregular das sacolas plásticas. Esse resultado, provavelmente, deve-se ao descompasso entre atitudes e comportamentos dos consumidores para concretizar de fato sua participação na implementação das ações alternativas com relação às sacolas plásticas ${ }^{[17]}$. A taxação de impostos sobre as sacolas plásticas é uma forma de deixar o consumidor ciente do custo do uso de sacolas plásticas e de motivá-lo a reduzir o consumo das mesmas.

Logo, é considerada essencial a intervenção do governo regulamentando e fiscalizando, assim como a cobrança de taxas sobre as sacolas plásticas, para que as ações iniciadas tenham resultados mais efetivos. De acordo com $\mathrm{Cadman}^{[26]}$, a taxação deve ser nas sacolas de plástico e papel, para que a regulamentação resulte em ganhos ambientais. Caso contrário, conforme constatado na Escócia, a taxação das sacolas de plástico pode resultar num aumento no consumo de sacolas de papel, o que não é uma alternativa sustentável ${ }^{[26]}$. Mesmo na Nova Zelândia, que tem indústria florestal forte, possui infra-estrutura para produção e reciclagem de papel ${ }^{[17]}$, a opção sacolas reutilizáveis foi considerada a melhor alternativa às sacolas plásticas descartáveis, em função dos aspectos negativos do uso de sacolas de papel.

A taxação de impostos sobre as sacolas plásticas exige exceções relacionadas às sacolas reutilizáveis ${ }^{[75]}$; sacolas para transportar peixe, carne e frango frescos; e sacolas para transporte exclusivo de frutas, vegetais, alimentos cozidos (frios ou quentes). Por outro lado, sacolas para transporte de produtos diversos em aviões e navios, portos e aeroportos podem ser sobretaxadas em relação aos demais usos. Um impacto negativo decorrente dessa sobretaxa foi a redução das compras desses produtos, porém logo superado ${ }^{[17]}$.

\section{Considerações Finais}

Apesar dos esforços em prol da melhoria contínua da cadeia de reciclagem serem ações sustentáveis, a afirmação de que tudo deve ser reciclado mecanicamente, pode nem sempre ser verdadeira do ponto de vista ambiental ${ }^{[2]}$. Da mesma forma que ser degradável e/ou biodegradável têm impactos relacionados ao desperdício de recursos naturais, água e energia ${ }^{[2]}$. Logo, as decisões devem ser específicas para cada região considerando a característica dos resíduos gerados, a infra-estrutura de gerenciamento de resíduos e a disponibilidade orçamentária existente, como se fosse um passo de cada vez. Como definido por Delgado et al. ${ }^{[76]}$, o que é iminente e constatável no dia a dia pode ser apenas a ponta do iceberg de um problema para outro e não, a solução.

Assim ações que favoreçam a redução das emissões de gases do efeito estufa; alcancem a cadeia mundial do plástico; reduzam a poluição do resíduo plástico; favoreçam o consumo sustentável; assegurem a biodiversidade e o equilíbrio dos ecossistemas, devem ter valoração acima das convencionais relações de custo versus benefício, para que possamos caminhar em direção a uma sociedade economicamente, socialmente e ambientalmente justa.

Especificamente, no caso das sacolas plásticas, ações voltadas para redução do consumo, associada à melhor qualidade das sacolas para assegurar sua reutilização para outros fins permitiriam atender aos itens redução e reutilização, consensualmente, aceitos como a melhor opção para gerenciamento dos resíduos plásticos. Já a viabilidade de ações complementares voltadas para o uso de embalagens compostáveis ou não, dependerá da infra-estrutura de gerenciamento de resíduos disponíveis, ou seja, essa ação deve estar associada à implantação de pontos de coleta seletiva com foco em RMB e aterros sanitários com área disponível para compostagem, assim como para captação dos gases gerados durante esse processo. Caso contrário, o problema se desloca de resíduos sólidos para resíduos gasosos, visto que aterros sanitários prevêem apenas o tratamento de efluentes líquidos. Nos casos em que a fração de resíduos compostáveis não justifica tais instalações, uma política voltada para utilização de materiais com alta resistência à (bio)degradação tem vantagens ambientais, já que são materiais potencialmente recicláveis e que não geram impactos secundários provenientes das atividades de reciclagem, desde que a população seja educada a reutilizar ou depositá-los em pontos de coleta específicos para resíduos plásticos, infra-estrutura indispensável para o gerenciamento de resíduos plásticos em geral.

\section{Conclusão}

Neste trabalho fez-se uma exposição ampla de informações que possam fundamentar discussões e avaliações sobre alternativas de substituição e destinações sustentáveis para sacolas plásticas descartáveis. De forma geral, considerando as diversas alternativas apresentadas e concordando com James e Grant ${ }^{[26]}$, é possível concluir que as sacolas reutilizáveis de material plástico reciclável sejam a melhor opção de substituição, ressalvando-se aqui que essas sejam destinadas à reciclagem mecânica ou à recuperação energética, dependendo da condição apresentada no final de vida útil. Por outro lado, não podendo ser simplista, verifica-se que há necessidade de estudos específicos para cada caso, com base nas mesmas hipóteses e mesmo contexto socioeconômico, para o que este trabalho objetivou ter contribuído.

\section{Agradecimentos}

Os autores agradecem aos pesquisadores Silas Derenzo, Maria Luiza O. D'Almeida e Maria Filomena A. Rodrigues do IPT, assim como prof. Dr. José Goldemberg do IEE/USP pelas oportunidades de discussão do tema que acabaram motivando a elaboração deste artigo.

\section{Referências Bibliográficas}

1. Zechendorf, B. - TIBTECH, 17, p.219 (1999).

2. Plastivida Instituto Sócio-Ambiental dos Plásticos. - "Embalagens plásticas: Mitos e Fatos", Dow \& Plastivida (2009). Disponível em $<$ http://www.plastivida.org.br/2009/pdfs/publicacoes_e_videos/2010_ FolderDowPlastivida.pdf $>$. 
3. Bridgman, P. \& Davis, G. - "Identifying Issues, and Policy Analysis", in: The Australian Policy Handbook, cap. 4 e 5, Allen \& Unwin (ed.), New South Wales, Australia (2000).

4. Shiber, J. G. - Mar. Pollut. Bull., 10, p.28 (1979). http://dx.doi. org/10.1016/0025-326X(79)90321-7

5. Ryan, P. G. - Mar. Pollut. Bull., 19, p.125 (1988). http://dx.doi. org/10.1016/0025-326X(88)90708-4

6. Palmisano, A. C. \& Pettigrew, C. A. - Biosci., 42, p.680 (1992). http:// dx.doi.org/10.2307/1312174

7. Shaw, D. G. \& Day, R. H. - Mar. Pollut. Bull., 28, p.39 (1994). http:// dx.doi.org/10.1016/0025-326X(94)90184-8

8. Derraik, J. G. B. - Mar. Pollut. Bull., 44, p.842 (2002). http://dx.doi. org/10.1016/S0025-326X(02)00220-5

9. Gregory, M. R. - Ocean Coast. Manag., 42, p.603 (1999). http://dx.doi. org/10.1016/S0964-5691(99)00036-8

10. Gregory, M. R. \& Ryan, P. G. - "Pelagic Plastics And Other Sea Borne Persistent Synthetic Debris: A Review Of Southern Hemisphere Perspectives", in: Marine Debris: Sources, Impacts and Solutions, p.49, J. M. Coe \& D. B. Rodgers (ed.), Springer-Verlag, New York (1997).

11. Henderson, J. R. - Mar. Pollut. Bull., 42, p.584 (2001). http://dx.doi. org/10.1016/S0025-326X(00)00204-6

12. Thompson, R. C.; Olsen, Y.; Mitchell, R. P.; Davis, A.; Rowland, S. J.; John, A. W. G.; McGonigle, D. \& Russell, A. E. - Sci., 304, p.838 (2004). PMid:15131299. http://dx.doi.org/10.1126/science.1094559

13. Moore, C. J.; Moore, S. L.; Leecaster, M. K. \& Weisberg, B. A. - Mar. Pollut. Bull., 42, p.1297 (2001). http://dx.doi.org/10.1016/S0025326X(01)00114-X

14. Takada, H. - Mar. Pollut. Bull., 52, p.1547 (2006). PMid:17113110. http://dx.doi.org/10.1016/j.marpolbul.2006.10.010

15. Morishige, C.; Donohue, M. J.; Flint, E.; Swenson, C. \& Woolaway, C. - Mar. Pollut. Bull., 54, p.1162 (2007). PMid:17572447. http://dx.doi. org/10.1016/j.marpolbul.2007.04.014

16. Donohue, M. J. - Mar. Pollut. Bull., 50, p.886 (2005). PMid:15982672. http://dx.doi.org/10.1016/j.marpolbul.2005.05.003

17. Tough, R. - "Plastic Shopping Bags: Environmental Impacts and Policy Options", Tese de Doutorado, Victoria University of Wellington, New Zeland (2007).

18. Njeru, J. - Geoforum , 37, p.1046 (2006). http://dx.doi.org/10.1016/j. geoforum.2006.03.003

19. González, N.; Mallo, M. \& Rivas, G. - "Plan de Acción Estratégico para la Gestión Sustentable de Bolsas Plásticas", Ministerio de Vivienda, Ordenamiento Territorial y Medio Ambiente, Montevideú (2009).

20. Austrália. Department of the Environment, Water, Heritage and the Arts. - "Plastic Bags". Disponível em: <http://www.environment.gov. au/settlements/waste/plastic-bags/index.html $>$.

21. Manrich, S. \& Santos, A. S. F. "An overview of recent advances and trends in plastic recycling". in: Conservation Recycling of Resources, Christian V. Loeffe (ed.), Nova Science Publishers, New York (2006).

22. Dmitrijevas, C. - "Análise de ecoeficiência de técnicas para tratamento e disposição de resíduos sólidos urbanos", Dissertação de mestrado, Instituto de Pesquisas Energéticas e Nucleares, Brasil (2010).

23. Blengini, G. A. - Resour. Conserv. Recycl., 52, p.1373 (2008). http:// dx.doi.org/10.1016/j.resconrec.2008.08.002

24. Nolan-ITU Pty Ltd. - "Plastic Retail Carry Bag Use 2002-2004 Consumption", Department of Environment and Heritage, Melbourne (2005).

25. Ecobilan - "Evaluation des Impacts Environnementaux des Saca de Caisse Carrefour: analyse du cycle de vie de casisse en plastique, paiper et materiau biodegradable”, in: Environment Group Research Report, Proposed Plastic Bag Levy- Extended Impact Assessment, J.
Cadman; S. Evans; M. Holland \& R. Boyd (eds.), AEA Technology Environment, Scottish Executive, Edinburgh (2005).

26. Cadman, J.; Evans, S.; Holland, M. \& Boyd, R. - "Environment Group Research Report, Proposed Plastic Bag Levy- Extended Impact Assessment", AEA Technology Environment, Scottish Executive, Edinburgh (2005).

27. James, K. \& Grant, T. - "Life Cycle Assessment of Degradable Plastic Bags", Royal Melbourne Institute of Technology - RMIT, Melbourne, Austrália (2005).

28. Fenton, R. - "The Winnepeg Packaging Project: Comparison of Grocery Bags", Department of Economics, University of Manitoba, Canadá (1991).

29. Nolan-ITU Pty Ltd. - "Plastic Shopping Bags-Analysis of Levies and Environmental Impacts", RMIT Centre for Design and Eunomia Reseach \& Consulting Ltd. Environment Australia, Department of the Environment and Heritage, Melbourne, Austrália (2002).

30. Davis, G \& Song, J. H. - Ind. Crops Prod., 23, p.147 (2006). http:// dx.doi.org/10.1016/j.indcrop.2005.05.004

31. Kim, M. \& Lee, S. - Carbohydr. Polym., 50, p.331 (2002). http:// dx.doi.org/10.1016/S0144-8617(02)00057-7

32. Bartle, I. - "Biopolymers: Packaging - A New Generation", in: Anais do ACTIN, Birmingham - UK, mar (2001).

33. Nolan-ITU Pty Ltd. - "Biodegradable Plastics-Developments and Environmental Impacts Prepared in assocation with ExcelPlas Austrália", (2002).

34. Scott, G. - Bioplast. Mag., 6, p.28 (2009).

35. Oxo-Biodegradable Plastics Association - «Hydro-biodegradable Plastic Production Process». Disponível em: <htpp://www.biodeg. org/files/uploaded/biodeg/Hydro-biodegradable_Plastic_Production_ Process.pdf $>$.

36. Ren, T. \& Patel, M. K. - Resour. Conserv. Recycl., 53, p.513 (2009). http://dx.doi.org/10.1016/j.resconrec.2009.04.005

37. Tabone, M. D.; Gregg, J. J.; Beckman, E. J. \& Landis, A. E. - Environ. Sci. Technol., 44, p.8264 (2010). http://dx.doi.org/10.1021/es101640n

38. Roy, P. K.; Surekha, P.; Rajagopal, C.; Chatterjee, S. N. \& Choudhary, V. - Polym. Degrad. Stab., 92, p.1151 (2007). http://dx.doi.org/10.1016/j. polymdegradstab.2007.01.010

39. Hudgins, M. - "Aerobic Landfill Studies from the USA", in: Anais da $1^{\text {a }}$ International Conference on Solid Waste, Rome, abr (1999).

40. Klauss, M. - Orbit Mag., July (2001).

41. Klauss, M. \& Bidlingmaier, W. - "Biodegradable polymer packaging: practical experiences of the model project Kassel", in: Biodegradable and Residual Waste Management, p.382, E.Papadimitrou \& E. Stentiford (eds.), CalRecovery Europe Ltd., Leeds (2004).

42. Favoino, E. - Waste Manag. World, p.95 (2003).

43. Linzner, R. \& Mostbauer, P. - "Composting and its impact on climate change with regard to process engineering and compost application - a case study in Vienna", in: Proceedings of Sardinia Tenth International landfill Symposium, Cagliari, CISA publisher (2005).

44. Ruston, S.; Gresham, P.; Bradshaw, K.; Purchas, C.; Bodle, K.; Coakley, J.; Wigley, G.; Handley, A. \& Buckland, S. - "Policy Instruments for Waste Minimisation and Management in New Zealand", Ministry for the Environment, Nova Zelândia (2002).

45. Michaud, J. C.; Farrant, L.; Jan, O.; Kjær, B. \& Bakas, I. "Environmental benefits of recycling", Waste \& Resources Action Programme - WRAP, Oxon (2010).

46. Mueller, W.; Fricker, K. \& Vogtmann, H. - Compost Sci. Util., 6, p.42 (1998).

47. British Plastics Federation - BPF \& Packaging and the Industrial Films Association. - "Plastics in Our Lives: Environmental and Safety Aspects of Plastic Packaging”, Factsheet, London (1993). 
48. Braskem. - "Braskem promove lançamento da pedra fundamental do projeto plástico verde". (2009). Disponível em: http://www. braskem.com.br/upload/portal_braskem/pt/sala_de_imprensa/ Lan\%C3\%A7amento\%20Pedra\%20PE\%20Verde.pdf.

49. Gielen, D. J.; Moriguchi, Y.; Yagita, H. - J. Clean. Prod., 10, p.589 (2002). http://dx.doi.org/10.1016/S0959-6526(01)00056-7

50. Smithers Rapra Technology Ltd. - "What is an oxo-biodegradable plastic?", Shropshire, Inglaterra (2010). Disponível em: <http://www. rapra.net/consultancy/biodegradable-plastic.asp >.

51. Oxo-Biodegradable Plastics Association - "Recycling of plastics", Londres (2010). Disponível em: <http://www.biodeg.org/positionpapers/recycling/?domain=biodeg.org $>$.

52. Haines, J. R. \& Alexander, M. - Appl. Microbiol., 28, p.1084 (1974).

53. Kyrikou, I. \& Briassoulis, D. - J. Polym. Environ., 15, p.227 (2007). http://dx.doi.org/10.1007/s10924-007-0063-6

54. Fenton, R. - Resour. Recycl., p.105 (1992).

55. Ciambrone, D. F. - "Environmental Life Cycle Analysis", CRC Press LCC, Lewis Publishers, Boca Raton, New York (1997).

56. McCarthy, S. P. - "Biodegradable Polymers for Packaging", in: Biotechnological Polymers Conference Proceedings, Lancaster, p.214 (1993).

57. Scott, G. - "Environmental biodegradation of polyolefins: when, why and how?", in: ICS Proceedings: Expert Group Meeting in Environmental Degradable Plastics: Present Status and Perspectives, Trieste, Italy, nov (2000).

58. Allen Consulting Group Pty Ltd - ACG. - "Phasing Out Light-Weight Plastic Bags a Cost Benefit of Alternative Approaches", Environment Protection and Heritage Council May (2006).

59. Waste \& Resources Action Programme - WRAP. - "Realising the value of recovered paper: An update", Oxon, Inglaterra, 2010.

60. Associação Brasileira da Indústria do PET - ABIPET. - "Análise de Ciclo de Vida - ACV', in: Anais do $4^{\circ}$ Censo da Reciclagem de PET no Brasil, São Paulo - SP, out (2008). Notas do debate sobre Análise de Ciclo de Vida - ACV.

61. Manrich, S. - Polímeros, 19, p.E4 (2009).

62. Santi, C. R.; Corrêa, A. C. \& Manrich, S. - Polímeros, 16, p.123 (2006).

63. Perez, I. S. B.; Manrich, S. \& Manrich, S. - Polímeros, 18, p.207 (2008).

64. Santos, A. S. F.; Agnelli, J. A. M. \& Manrich, S. - Polímeros, 4, p.307 (2004).
65. Danella Junior, O. J.; Santana, R. M. C.; Manrich, S. \& Manrich, S. J. Appl. Polym. Sci., 88, 9, p.2346 (2003). http://dx.doi.org/10.1002/ app.11889

66. Manrich, S.; Ravazi, R.; Danella Junior, O. J.; Santana, R. M. C. \& Manrich, S. - "Recycling of plastics waste into value added film products", in: Proceedings of REWAS'2004 - Global Symposium on Recycling Waste Treatment and Clean Technology, vol. II, p.1671, Madrid, set (2004).

67. Manrich, S.; Danella Junior, O. J.; Santi, C. R.; Corrêa, A. C.; Mortara, A. A. \& Giacomazzi, L. - "Composições para papéis sintéticos e filmes ecológicos para escrita e impressão, papéis sintéticos e filmes obtidos a partir dessas e uso dos mesmos”. Patent PI 0701443-0 (2007).

68. Franco, M. - Rev. Época, Ed. Globo, 643, p.120 (2010).

69. Franco, M. - Rev. Época, Ed. Globo, 644, p.10 (2010).

70. Borges, J. R. V. \& Manrich, S. - "Análise de propriedades superficiais, óticas e de printabilidade em filmes multicamadas de papel sintético e em filmes de nanocompósitos recobertos com diferentes coatings" (2009). Resultados ainda não divulgados.

71. Brandrup, J. - "Ecology and economy of plastic recycling", in: Proceedings of the International Scientific Workshop on Biodegradable Plastics and Polymers, Stockholm, Sweden, june (1998).

72. Jackson, T. - "Material Concerns: Pollution, Profit and Quality of Life", Routledge, London (1996). http://dx.doi.org/10.4324/9780203435557

73. Hyder Consulting. - "Plastic Retail Carry Bag Use 2002-2005 Consumption", Department of the Environment and Heritage, Melbourne, Austrália (2006).

74. Werzbitzki, J. J. - "O problema das sacolinhas plásticas", Jornal Nacional (16.07.2010). Disponível em: <http://g1.globo.com/jornalnacional>.

75. Environmental Protection and Heritage Council. - "Consultation Regulatory Impact Statement - RIS Investigation of Options to Reduce the Environmental Impact of Plastic Bags", Melbourne, Austrália (2007).

76. Delgado, G.; Saraiva, I.; Lima Junior, J. A. T.; Xavier, L. S. \& Peixoto, J. A. A. - "A metodologia de análise do ciclo de vida, apioada pelo software umberto, como ferramenta de gestão na perspectiva da sustentabilidade: um estudo de caso", in: Anais do $4^{\circ}$ Simpósio de Excelência em Gestão e Tecnologia, Foz do Iguaçu - PR, out. (2007).

Enviado: $17 / 02 / 11$

Reenviado: 04/07/11

Aceito: $18 / 08 / 11$ 